\title{
STUDY ON PHYSICAL EDUCATION AND SPORT
}

\author{
Raiola, G. and A. Di Tore \\ Department of Human, Philosophical and Formation Sciences, \\ Faculty of Formation Sciences, University of Salerno, Italy
}

Received 2012-04-24, Revised 2012-05-10; Accepted 2013-05-15

\begin{abstract}
MIUR enacted last year the new Guidelines of Physical Education and Sport to improve the sport activity into the school through the sport school association and gives, for this aim, only $33 \%$ of amount of economical resources that, in the past years, allocated for extra activity of physical education and sport. From a case study to compare data between 2 years of a sample of 10 schools of Naples, 6 schools decreased sports activity, 4 schools increased little bit and only 1 increased because had added own economical resource. Furthermore this one also deliberated a school sport association in collaboration to sport association as suggests new Guidelines. The aim of this study is to know which process the school adopted. Method is case study to describe the process and steps. All 10 schools confirm the past sport activities in different forms with several percentages among the schools are very good in consideration of the bad actual context of public school. But the significant decrease of number of students, which are generally distributed in every school, must do a reflection on general situation of high sport left. The 7 schools utilized only the economical ministerial resource and only 2 schools utilized economical ministerial resources is the demonstration of low culture in physical education and sport into school. Furthermore, the low additional own economical resources is relevant to demonstrate the gravity of situation. The datum of only 1 school added own economical resource in congruent amount means that just the $10 \%$ of schools understand the spirit of change according to the new Guidelines of Physical Education and Sport. The study suggests to start an investigation on public sport education service offered by school and by sport association and to establish a specific committee to research on this phenomenon to carry out the data to know every aspect of it.
\end{abstract}

Keywords: Case Study, Education Offer Planning (POF), Regulation Document, Sport Association

\section{INTRODUCTION}

Nowadays, the Physical Education and Sport in Italian school meets several following problems: decreasing amount of compulsory physical education, decreasing quality of physical education, high amount of non-exercising pupils, exempted pupils from physical education classes, stagnate physical fitness and motor productivity of youth, insufficient solicitude of disabled pupils, lack of control of Physical Education, weak of social and financial honor of Physical Education and Sport teachers and low interest of graduates, especially of teaching specialization to work in their own profession (MIUR, 2009). To change this status, it should contribute a new project of education. It is established on the basis of educational domains-human and nature, human and technique, an individual, Society, Culture, Mathematical and Logical Thinking, Language and Communication, Health and Movement, Educational area Health and movement is elaborated in subject physical and sport education in New National Indication (MIUR, 2003), Indication for Curriculum (MIUR, 2007) into modules that include health and its impairment, healthily life style, physical fitness and motor performance, sport activities of movement regime. Furthermore, the Minister of Education, University and Research implements the Sports Student Championship Games every year and gives economical special resource to do teaching in extra time school by the teachers of physical education.

This process is evaluated by school in its internal path and, at the end of it, it is approved. Due to the decreasing

Corresponding Author: Raiola, G., Department of Human, Philosophical and Formation Sciences,

Faculty of Formation Sciences, University of Salerno, Italy 
of economical resource to destination to school, the economical special resource for Sports Student Championship Games in many schools there is not the intention to do education in extra time school. For this reason, the Minister wants to give a response to this problem doing a series of administrative measures to increase motor and sport practice in school. Furthermore, by Italian National Olympic Committee (CONI) researching, it had carried out the decrease of the sport practitioners and to charge this debt of practitioners to deficit by school. Thus, the Minister of Education University and Research had, last year, enacted the experimental project called New Guidelines of Physical Education and Sport into the school (MIUR, 2009).

The past study was been the investigation on variation of sport practitioners in a sample of 100 customers that have submitted questionnaire with the specific parameters ... (Raiola and D'Isanto 2011) as a way to analyze the association between indicators and descriptors of phenomenon of sport practices. In the same way, it would apply the method research into the school to investigate the process. So, it is useful to know the steps and its dynamic in order to sequence, consistence and timing. Particularly, it has to work in following way. What the solutions were that the school had adopted to resolve the problem to pay the teachers of physical education for the extra work time school. The Minister of Education University and Research results after an year that it is enacted the experimental project called New Guidelines of Physical Education and Sport (MIUR, 2009) with the purpose to improve the motor and sports activities into the school. To realize the purpose to improve motor sport activities into the school, it needed the economical added resource to pay the teachers for the extra work time. Because they have to organize, train and do the work activities, including the competitions to the others school. The special economical resources, that the Minister has given and is going to give has decreased of $66 \%$ than the past time. This New Guidelines of Physical Education and Sport (MIUR, 2009) to improve the sport activity establishes a new organizational tool inside the school called School Sport Center. It consists in internal sport association but it needs of new economical resource to pay the teachers for their added jobs. The question was how it is possible to increase the sport practitioners if the economical resource decreases. Particularly how the School Sport Center can increase the motor and sports activity into the school and to offer a more sport service for the student if money is not enough as such as the past years. The special objective of past study was to know if there was the increase or decrease of motor and sport activity in schools of Naples and what was the solution that the school had adopted in the past year to resolve how to pay the teachers. In particular, the aim of the past study (D'Isanto and Raiola, 2010) was to investigate on variation of sport student practitioners in increasing or decreasing motor and sport activity in schools of Naples and what solutions were that the school had adopted to resolve the problem to pay the teachers of physical education in order to new situation (Table 1a). By CONI research, it had carried out the decrease of the sport practitioners and the MIUR had, consequently, enacted the experimental project to improve the motor and sports activities into the school.

Thus, it needed economical resource to pay the teachers for organizing, training and doing the competitions, but the special economical resources, Minister had usually given last year had decreased, as it has already written, of $66 \%$. The utilized method for the past study was the case study through quantitative and qualitative methods. Firstly, it requested to a sample of 10 schools to start an investigation in order to collect data on motor and sports activity and its costs in the past years. Secondly, it collected data on new and old motor and sports activities. Thirdly, it had compared all data to identify the school that had increased the motor and sport activities. Finally, it had found out those schools that increased the motor and sport activity, the economical resource to resolve the question and it had described the process of administrative activities and its steps. The plenty sample of 10 school had confirmed the motor and sports activities in past form but it decreased the quantitative of motor and sports activity for each student. They used only the ministerial specific economical resources. Only 4 schools had increased the sport activities in several kinds to except the additional amount economical resources. Only one school had added own economical resource to improve the resources that the Minister had usually given. This school had deliberated the school sport center with the joint collaboration to sport association to develop the educational purposes of motor and sports activity and not sport competition purpose. The order of process was the following:

- It requested to a sample of 10 school of Naples, that are interested in research and to start an investigation in order to collect data on motor and sport activity and its costs in the past years

- It collected data on new and old motor and sports activities

- It compared all data to identify the school that increased the sport activities 
Table 1a. Data sheet

\begin{tabular}{|c|c|c|c|c|c|c|c|c|c|c|}
\hline Number of schools & 1 & 2 & 3 & 4 & 5 & 6 & 7 & 8 & 9 & 10 \\
\hline $\begin{array}{l}\text { Actual student participation } \\
\text { Past student participation } \\
\text { School economical resource in ranges } \\
\text { until } 33 \% \text { nothing additional resources until } \\
66 \% \text { a little bit additional resources } \\
\text { until } 99 \% \text { congruent additional resources } \\
\text { Collaboration with sport association in ranges until } \\
33 \% \text { nothing collaboration to sport association until } \\
66 \% \text { a little bit collaboration to sport association but } \\
\text { a marginal role until 99\% full collaboration to sport } \\
\text { association with a significative role }\end{array}$ & & & & & & & & & & \\
\hline
\end{tabular}

Table 1b. Data of ten schools

\begin{tabular}{|c|c|c|c|c|c|c|c|c|c|c|}
\hline & $\begin{array}{l}1^{\wedge} \\
\text { School\% }\end{array}$ & $\begin{array}{l}2^{\wedge} \\
\text { School } \%\end{array}$ & $\begin{array}{l}3^{\wedge} \\
\text { School } \%\end{array}$ & $\begin{array}{l}4^{\wedge} \\
\text { School } \%\end{array}$ & $\begin{array}{l}5^{\wedge} \\
\text { School } \%\end{array}$ & $\begin{array}{l}6^{\wedge} \\
\text { School\% }\end{array}$ & $\begin{array}{l}7^{\wedge} \\
\text { School } \%\end{array}$ & $\begin{array}{l}8^{\wedge} \\
\text { School } \%\end{array}$ & $\begin{array}{l}9^{\wedge} \\
\text { School\% }\end{array}$ & $\begin{array}{l}10^{\wedge} \\
\text { School } \%\end{array}$ \\
\hline New partecipation & 30 & 27 & 29 & 33 & 38 & 24 & 29 & 32 & 30 & 26 \\
\hline Old participation & 32 & 33 & 30 & 36 & 45 & 28 & 33 & 30 & 39 & 28 \\
\hline Economical resources & 33 & 33 & 66 & 33 & 66 & 33 & 33 & 99 & 33 & 33 \\
\hline $\begin{array}{l}\text { Collaboration range } \\
\text { sport association }\end{array}$ & 33 & 33 & 33 & 66 & 66 & 33 & 33 & 99 & 33 & 33 \\
\hline
\end{tabular}

Table 2. Data of percentage student sport activities student

\begin{tabular}{lllll}
\hline & $\begin{array}{l}\text { New\% students } \\
\text { participants }\end{array}$ & $\begin{array}{l}\text { Old \% students } \\
\text { participants }\end{array}$ & $\begin{array}{l}\text { \% economical } \\
\text { resources }\end{array}$ & $\begin{array}{l}\text { Collaboration range } \\
\text { sport association }\end{array}$ \\
\hline School 1 & 30 & 32 & 33 & 33 \\
School 2 & 27 & 33 & 33 & 33 \\
School 3 & 29 & 30 & 66 & 33 \\
School 4 & 33 & 36 & 33 & 66 \\
School 5 & 38 & 45 & 66 & 66 \\
School 6 & 24 & 28 & 33 & 33 \\
School 7 & 29 & 33 & 99 & 93 \\
School 8 & 32 & 30 & 33 & 33 \\
School 9 & 30 & 39 & 33 & 33 \\
School 10 & 26 & 28 & 33 & \\
\hline
\end{tabular}

- It found out the school that increased the motor and sport activity, what the economical solution was and it described the details and the steps of the process

The data on participation of external sport association and economical resource was been Tabled by three ranges as following:

- From 0\% until 33\% for the indicator of without participation of sport associations participation and for the indicator regarding the additional economical resource without additional economical resource

- From 34\% until $66 \%$ for the indicator of real participation of sport associations but with a marginal role in sport organization and for the indicator regarding the additional economical resource with additional resource but a little bit
- From $67 \%$ until $99 \%$ for the indicator of full participation of sport associations with a significant role and for the indicator regarding the additional economical resource with additional economical resource with a significant amount of money (Table 1b)

The past results were the following. Table 1 shows that all 10 school confirms the past sport activities in different forms with several percentage among the schools but with a significant decrease of number of students that are generally distributed in every schools. The 7 schools utilized only the economical ministerial resource, while 2 schools utilized economical ministerial resources and to add own economical resources but in a little bit quantitative. Only one school added own economical resource in congruent amount. The two 
schools added a little bit of economical resource has a good percentage of student participation that is higher than the other schools and did not add the economical resource. Only one school increased the sport activities but it gave a congruent additional economical resource. All schools deliberated the school sport center trough a correct process as such as the administrative and juridical parameters. Only one school established a joint plenty collaboration to sport association to develop the educational purposes of sport activity and not the sport competitive purpose. Every school confirmed the institution of Sport Student Championship Games and so the sport activity in several forms utilizing the ministerial specific economical resources: It was just of $33 \%$ than the past years. Every school had many problems to participate to competitive forms of Sport Student Championship Games (Table 2). Nowadays, for the data that was been decrypted in this introduction it could be examined the school had made a better performance in order the three indicators and its descriptors. The aim of this study is to know which process the better school had adopted.

\section{MATERIALS AND METHODS}

Case study to describe the process and steps. The Case study is a research methodology common in social science (George and Bennett, 2005).

It is based on an in-depth investigation of a single individual, group, or event to explore causation in order to identify underlying principles. Rather than using samples and following a rigid protocol to examine limited number of variables, case study methods involve an in-depth, longitudinal examination of a single instance or event: a case. They provide a systematic way of looking at events, collecting data, analyzing information and reporting the results (Dul and Hak, 2007). As a result the researcher may gain a sharpened understanding of why the instance happened as it did and what might become important to look at more extensively in future research. Case studies lend themselves to both generating and testing hypotheses (Eisenhardt, 1989). Another suggestion is that case study should be defined as a research strategy, an empirical inquiry that investigates a phenomenon within its real-life context. Case study research means single and multiple case studies, can include quantitative evidence, relies on multiple sources of evidence and benefits from the prior development of theoretical propositions. Case studies should not be confused with qualitative research and they can be based on any mix of quantitative and qualitative evidence
(Bent, 2006). Single subject research provides the statistical framework for making inferences from quantitative case-study data. This is also supported and well-formulated in: The case study is a research approach, situated between concrete data taking techniques and methodological paradigms (Lamnek, 2005). In this study it uses a case study trough qualitative and quantitative method with mix approach: case study and statistical data.

\section{RESULTS}

The study shows the following descriptive data (Table 3):

- Discussion and deliberation, inside the school organisms, of School Sport Association and to include sports activity in Offer Education Planning (POF)

- Allocation of additional own economical resources that needs to realize the sports activity

- Collaboration with sport association to aim indications of official ministerial document

- Participation at Sports School Championship (CSS) for several sports and Youth Games

- Payment of physical education teachers using own economical resources

- Transfer from Minister to school economical current resources and then payment of physical education teachers

\section{DISCUSSION}

Table 2, Fig. 1 and 2 all 10 school confirm the past sport activities in different forms with several percentage among the schools is very good in consideration of the bad actual context of public school. But the significant decrease of number of students, that are generally distributed in every schools, must do a reflection on general situation of high sport left. The 7 schools utilized only the economical ministerial resource and only 2 schools utilized economical ministerial resources is the demonstration of low culture in physical education and sport into school. Furthermore, the low additional own economical resources is relevant to demonstrate the gravity of situation. The datum of only 1 school added own economical resource in congruent amount means that just the $10 \%$ of schools understand the spirit of change according to the new Guidelines of Physical Education and Sport (MIUR, 2009). 


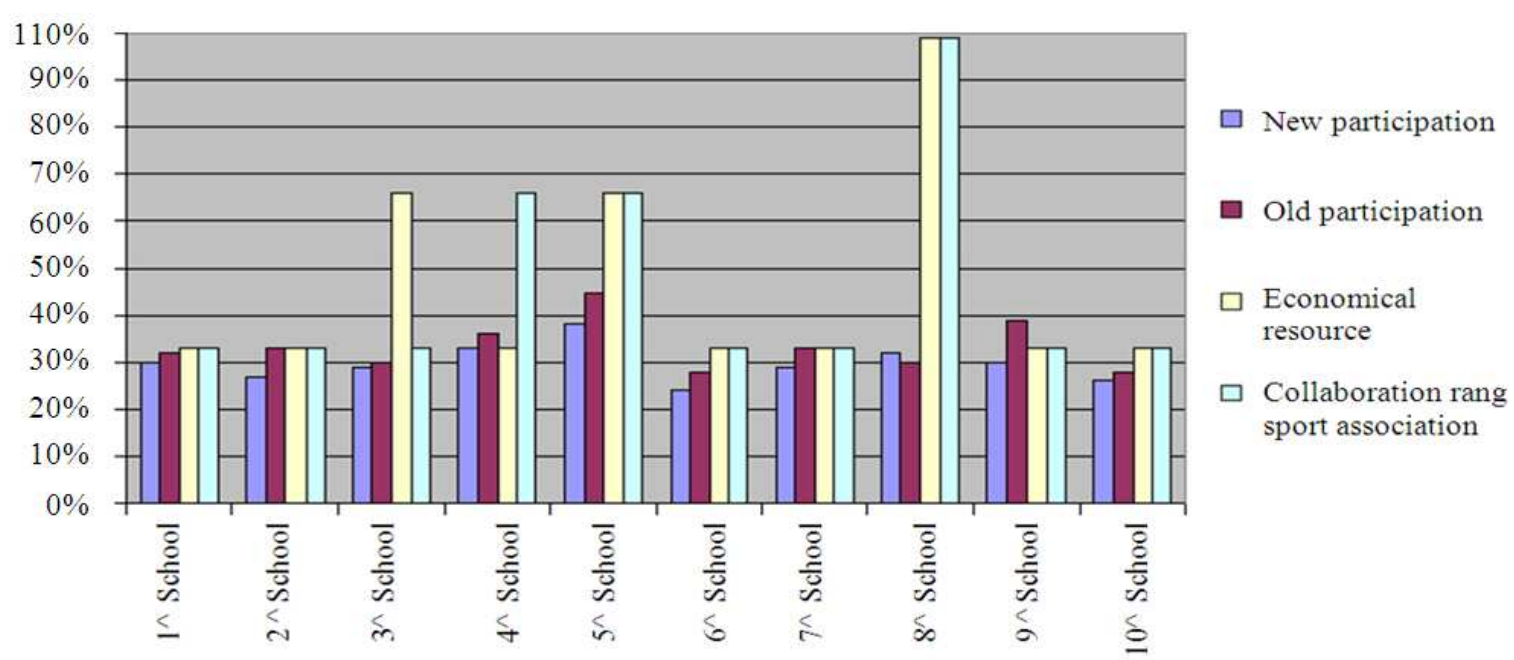

Fig. 1. Graphic on percentage sport activities student

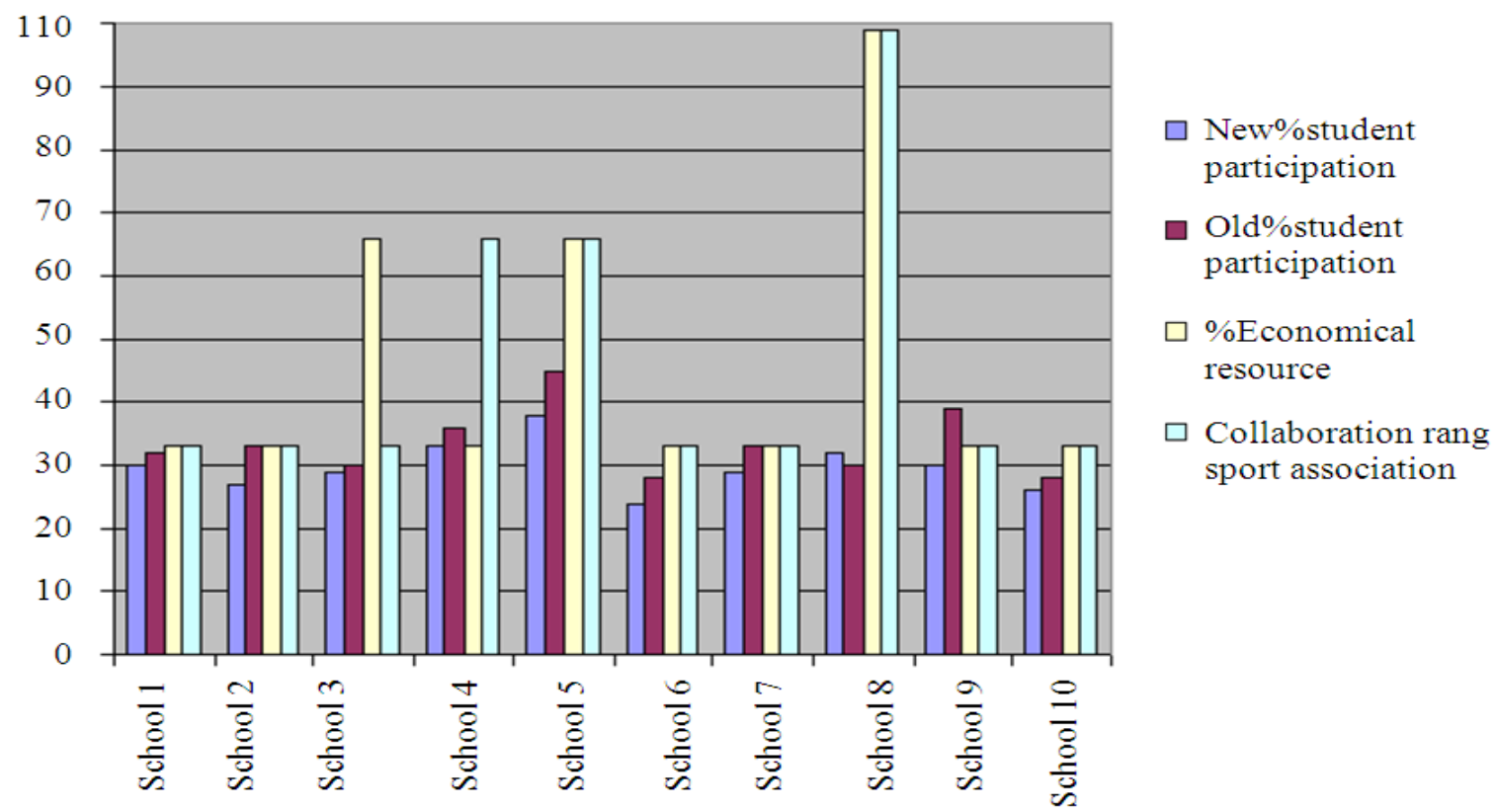

Fig. 2. Graphic on percentage student sport activities student

Table 3. Results case study descriptive data

\begin{tabular}{ll}
\hline Step & Description of single action \\
\hline 1 & $\begin{array}{l}\text { Discussion and deliberation, inside the school organisms, of School Sport Association } \\
\text { and to include sports activity in Offer Education Planning (POF) activity }\end{array}$ \\
3 & Collaboration with sport association to aim indications of official ministerial docu \\
2 & Allocation of additional own economical resources that needs to realize the sports ment \\
4 & Participation at Sports School Championship (CSS) for several sports and Youth Games \\
5 & Payment of physical education teachers using own economical resources \\
6 & Transfer from Minister to school economical current resources and then payment of physical education teachers \\
\hline
\end{tabular}


In the same way is the datum that only 1 school increased the sport activities because of it gives a congruent additional economical resource and so the school is according to the sense and spirit of the new Guidelines of Physical Education and Sport (MIUR, 2009).

\section{CONCLUSION}

The case study of only school established a joint plenty collaboration to sport association to develop the educational purposes of sport activity and not the sport competitive purpose is an ambiguous datum. The results of case study descriptive data open a new reflexion on the reality into the school. Offer Educational Planning (POF) is the tool to solve a problem of lack the joining the sport association and the school in unique physical education and sport organism. Furthermore, if in one hand it is positive for the educative purpose for the school and not vice versa for the competitive purpose for the sport association, in the other hand the quantitative datum is not positive for the lowest percentage of the school occurs in this investigation. The problem about the decrease of ministerial economical resource is nowadays metabolized by the school. So the schools have to be adapted as soon as possible in changing of the scenario of public education without economical resources as well as in the past years. It had shown a complex total negative data on this changing for the physical education and sport into the school. Probably, the sample is not significant because of the schools are in the same territory that is same social problems. It suggests to start an investigation on public sport education service offered by school and by sport association and to establish a specific committee to research on this phenomenon to carry out the data to know every aspect of it. It needs in future to investigate on sport education service offered both school and sport association to agree an institutional collaboration which does not have a distinction between competitive sport and educative one.

\section{REFERENCES}

Bent, F., 2006. Five misunderstandings about case- study research. Q. Inquiry, 12: 219-245. DOI: $10.1177 / 1077800405284363$

D'Isanto, T. and G. Raiola, 2010. State of art study of the change of physical education and sport in secondary school in Italy. Phys. Educ. Sport/Sci., Move. Health Series, 10: 663-667.

Dul, J. and T. Hak, 2007. Case Study Methodology in Business Research. 4th Edn., ButterworthHeinemann/Elsevier, Boston, MA., ISBN: 100750681969, pp: 302.

Eisenhardt, K.M., 1989. Building theories from case study research. Acad. Manage. Rev., 14: 532-550. DOI: $10.5465 / A M R .1989 .4308385$

George, A.L. and A. Bennett, 2005. Case Studies and Theory Development in the Social Sciences. 1st Edn., MIT Press, Cambridge, Mass, London, ISBN: 10- 0262072572, pp: 331.

Lamnek, S., 2005. Qualitative Sozialforschung: Lehrbuch. 4th Edn., Beltz, PVU, Weinheim, ISBN10: 3621275444 , pp: 808.

MIUR, 2003. Indicazioni nazionali.

MIUR, 2007. Indicazioni per il curricolo Ministero della Pubblica Istruzione, Universita e Ricerca.

MIUR, 2009. Linee guida per l'educazione fisica e sportiva.

Raiola, G. and T. D'isanto 2011. New research approach to rebuild sport facilities. J. Soc. Sci., 7: 306-308. DOI: $10.3844 /$ jssp.2011.306.308 